\title{
Changes in the dispensing of opioid medications in Canada following the introduction of a tamper-deterrent formulation of long-acting oxycodone: a time series analysis
}

\author{
Tara Gomes PhD, Andrea Mastorakos HBSc, J. Michael Paterson MSc, Ingrid Sketris PharmD MPA(HSA), \\ Patricia Caetano PhD, Simon Greaves MSc, David Henry MBChB; for the Canadian Network for \\ Observational Drug Effect Studies Investigators*
}

\section{Abstract}

Background: In February 2012, a reformulated tamper-deterrent form of long-acting oxycodone, OxyNeo, was introduced in Canada. We investigated the impact of the introduction of OxyNeo on patterns of opioid prescribing.

Methods: We conducted population-based, cross-sectional analyses of opioid dispensing in Canada between 2008 and 2016 . We estimated monthly community pharmacy dispensing of oral formulations of codeine, morphine, hydromorphone and oxycodone, and a transdermal formulation of fentanyl, and converted quantities to milligrams of morphine equivalents (MMEs) per 1000 population. We used time series analysis to evaluate the effect of the introduction of OxyNeo on these trends.

Results: National dispensing of long-acting opioids fell by $14.9 \%$ between February 2012 and April 2016, from 36098 MMEs to 30716 MMEs per 1000 population $(p<0.01)$. This effect varied across Canada and was largest in Ontario (reduction of $22.8 \%)(p=$ 0.01 ) and British Columbia (reduction of $30.0 \%)(p=0.01)$. The national rate of oxycodone dispensing fell by $46.4 \%$ after the introduction of OxyNeo $(p<0.001)$; this was partially offset by an increase of $47.8 \%$ in hydromorphone dispensing ( $p<0.001)$. Although dispensing of immediate-release opioids was a substantial contributor to overall population opioid exposure across Canada, it was unaffected by the introduction of OxyNeo ( $p>0.05$ in all provinces).

Interpretation: The findings suggest that the introduction of a tamper-deterrent formulation of long-acting oxycodone in Canada, against a background of changing public drug benefits, was associated with sustained changes in selection of long-acting opioids but only small changes in the quantity of long-acting opioids dispensed. This illustrates the limited effect a tamper-deterrent formulation and associated coverage policy can have when other, non-tamper-deterrent alternatives are readily available.

lthough opioids have an important clinical role in the treatment of acute and chronic pain, the use of these products to treat chronic noncancer pain remains controversial, as their long-term use has been associated with substantial side effects, including abuse, addiction and premature death from accidental overdose..$^{1,2}$ Canada and the United States have historically high levels of prescription opioid consumption per capita, ${ }^{3}$ with rates that are about double those observed in the European Union, Australia and New Zealand. ${ }^{4}$ In Canada, prescription opioid consumption increased nearly fourfold between 1999 and $2010,{ }^{5}$ despite the fact that the proportion of Canadians who reported experiencing chronic pain did not change substantially over this period. ${ }^{6}$ In Ontario, the rate of opioid prescribing rose by 29\% between 1991 and 2007; the increase was largely driven by an $850 \%$ increase in prescribing of oxycodone. $^{7}$
This rising prevalence of oxycodone prescribing in Ontario has been attributed to the addition of long-acting oxycodone (OxyContin) to the provincial drug benefit formulary in 2000, raising serious concerns regarding its potential misuse and abuse. ${ }^{7}$ The ability to circumvent the long-acting properties of the oxycodone tablet by chewing

Competing interests: Tara Gomes has received unrestricted grant funding from the Ontario Ministry of Health and Long-Term Care. No other competing interests were declared.

*The list of members appears at the end of the article.

This article has been peer reviewed.

Correspondence to: Tara Gomes, GomesT@smh.ca

CMAJ Open 2017. DOI:10.9778/cmajo.20170104 
or grinding the pills for inhalation or injection has been widely cited as a contributing factor to rising rates of opioid addiction and overdose across North America. ${ }^{8,9}$ In February 2012, the manufacturer of OxyContin discontinued its production and replaced it with a new formulation, OxyNeo, in an attempt to address concerns related to the misuse of their controlled-release oxycodone product. Specifically, OxyNeo tablets were hardened to make them more difficult to misuse (i.e., crush, chew), and, when dissolved, these tablets form a gel that is difficult to inject. ${ }^{10}$ In the US, Purdue Pharma similarly reformulated OxyContin 2 years earlier. The response of the Canadian public drug insurance plans to the new formulation varied, with provinces such as Alberta granting OxyNeo the same full benefit status afforded to OxyContin, while others severely restricted access because of concerns regarding the historically high rates of oxycodone misuse. ${ }^{11}$ Given that OxyNeo was the first opioid with tamper-deterrent properties in Canada, and because opioid-prescribing practices vary widely across Canada, ${ }^{12}$ we performed a study to explore the impact of the introduction of $\mathrm{OxyNeo}$ against a background of changing provincial drug insurance plan formulary changes on the quantity of opioids prescribed across the country.

\section{Methods}

\section{Setting and design}

We conducted a population-based, repeated cross-sectional analysis of prescribing of long-acting opioids across Canada between May 1, 2008, and Apr. 30, 2016. We studied dispensing of oral formulations of codeine, morphine, hydromorphone and oxycodone, and a transdermal formulation of fentanyl (Table 1). Propoxyphene and meperidine were excluded given their limited prescribing during the study period, and methadone and buprenorphine were excluded as they are used primarily to treat opioid use disorder in Canada.

\section{Sources of data}

We used the QuintilesIMS CompuScript database to identify monthly quantities of retail pharmacy prescriptions for all eligible opioid analgesics dispensed during the study period. This database captures data from a representative sample of about 6000 community pharmacies and projects prescription quantities dispensed at the national and provincial level. These projections incorporate information about the number of pharmacies in each region, the distance between participating pharmacies and the size of the pharmacies. These data are continuously monitored and verified by QuintilesIMS to ensure that they are within the standards set for quality control, are representative at both the provincial and national level and are regularly used for research purposes. ${ }^{12,13}$ Specifically, at the national level, over $79 \%$ of prescriptions dispensed are captured by this panel of pharmacies, with a sampling error rate of about 3\% (QuintilesIMS). The sampling error for monthly estimates at the provincial level can reach higher levels, although it generally does not exceed $5 \%-10 \%$.

\section{Outcomes}

We calculated the total quantity of opioid dispensed each month by multiplying the units by the formulation strength and expressed the quantity in milligrams of morphine equivalents (MMEs) using conversion ratios reported by the National Opioid Use Guideline Group. ${ }^{14}$ With fentanyl patches, conversion into estimates of MMEs can be difficult given that the patches are meant to be used over 3 days but are sometimes used for shorter periods. In this study, we assumed that all patches were used for 3 days, accepting that this may overestimate MME exposure in some people. Our primary measures of interest were the rate of dispensing of long-acting opioids by province and the national rate of dispensing of long-acting opioids stratified by opioid type. In a secondary analysis, we analyzed trends in dispensing of immediate-release opioids by province and prescribing of long-acting opioids by opioid type for each province sepa-

\begin{tabular}{|c|c|c|c|c|c|}
\hline \multirow[b]{2}{*}{ Drug } & \multirow[b]{2}{*}{$\begin{array}{c}\text { Morphine } \\
\text { conversion factor }\end{array}$} & \multicolumn{2}{|c|}{$\begin{array}{l}\text { Long-acting opioid } \\
\text { formulations }\end{array}$} & \multicolumn{2}{|c|}{$\begin{array}{l}\text { Short-acting opioid } \\
\text { formulations }\end{array}$} \\
\hline & & Formulation & $\begin{array}{l}\text { Unit dosage } \\
\text { range }\end{array}$ & Formulation & $\begin{array}{l}\text { Unit dosage } \\
\text { range }\end{array}$ \\
\hline Oxycodone & 1.71 & Oral & $5-80 \mathrm{mg}$ & Oral & $2.5-20 \mathrm{mg}$ \\
\hline Hydromorphone & 4.5 & Oral & $3-32 \mathrm{mg}$ & Oral & $1-8 \mathrm{mg}$ \\
\hline Morphine & 1 & Oral & 10-200 mg & Oral & $1-60 \mathrm{mg}$ \\
\hline \multirow[t]{6}{*}{ Fentanyl } & $12 \mu \mathrm{g} / \mathrm{h}: 52$ & Transdermal & $12-100 \mu \mathrm{g} / \mathrm{h}$ & - & - \\
\hline & $25 \mu \mathrm{g} / \mathrm{h}: 97$ & & & & \\
\hline & $37 \mu \mathrm{g} / \mathrm{h}: 157$ & & & & \\
\hline & $50 \mu \mathrm{g} / \mathrm{h}: 202$ & & & & \\
\hline & $75 \mu \mathrm{g} / \mathrm{h}: 292$ & & & & \\
\hline & $100 \mu \mathrm{g} / \mathrm{h}: 382$ & & & & \\
\hline Codeine & 0.15 & Oral & $50-200 \mathrm{mg}$ & Oral & $5-60 \mathrm{mg}$ \\
\hline
\end{tabular}


rately. We report dispensing rates as MMEs dispensed per 1000 population, using Statistics Canada census population estimates ${ }^{15}$ as the denominator.

We compared patterns of dispensing of long-acting opioids in the first (May to October 2008) and last (November 2015 to April 2016) 6-month periods of the study by province to establish any changes that occurred over the study period. Measures captured at each observation point included opioid prescription rate, average number of opioid units dispensed per prescription and opioid quantity (in MMEs) dispensed per prescription. We calculated ratios (last 6 months/initial 6 months) of the prescription rate and quantities dispensed as measures of variance over time.

\section{Statistical analysis}

We used time series analysis to characterize the impact of the introduction of OxyNeo to the provincial drug insurance plan formularies on the rate of dispensing of long-acting and immediate-release opioids in Canada using a ramp function in interventional autoregressive integrated moving average models. ${ }^{16,17}$ All models were fitted with the use of data from the beginning of the study period to April 2013. We excluded data after this time point to avoid modelling more remote shifts in prescribing. We examined model fit using white noise probabilities, autocorrelation functions and the Ljung-Box test (see Appendix 1, available at www.cmajopen.ca/content /5/4/E800/suppl/DC1, for fit of specific models). All analyses used a type 1 error rate of 0.05 as the threshold for statistical significance and were carried out with the use of SAS statistical software version 9.3 (SAS Institute).

\section{Results}

Over the 8-year study period, 1739057621 long-acting opioid tablets and transdermal patches were dispensed in Canada. The quantity dispensed differed by opioid type, with oxycodone tablets accounting for 726477071 (41.8\%) of all units dispensed, hydromorphone for 443604461 units (25.5\%), morphine for 408648392 units $(23.5 \%)$, codeine for 99856627 units $(5.7 \%)$ and fentanyl patches for 60471070 units (3.5\%). In addition, 7350703901 immediaterelease opioid tablets were dispensed.

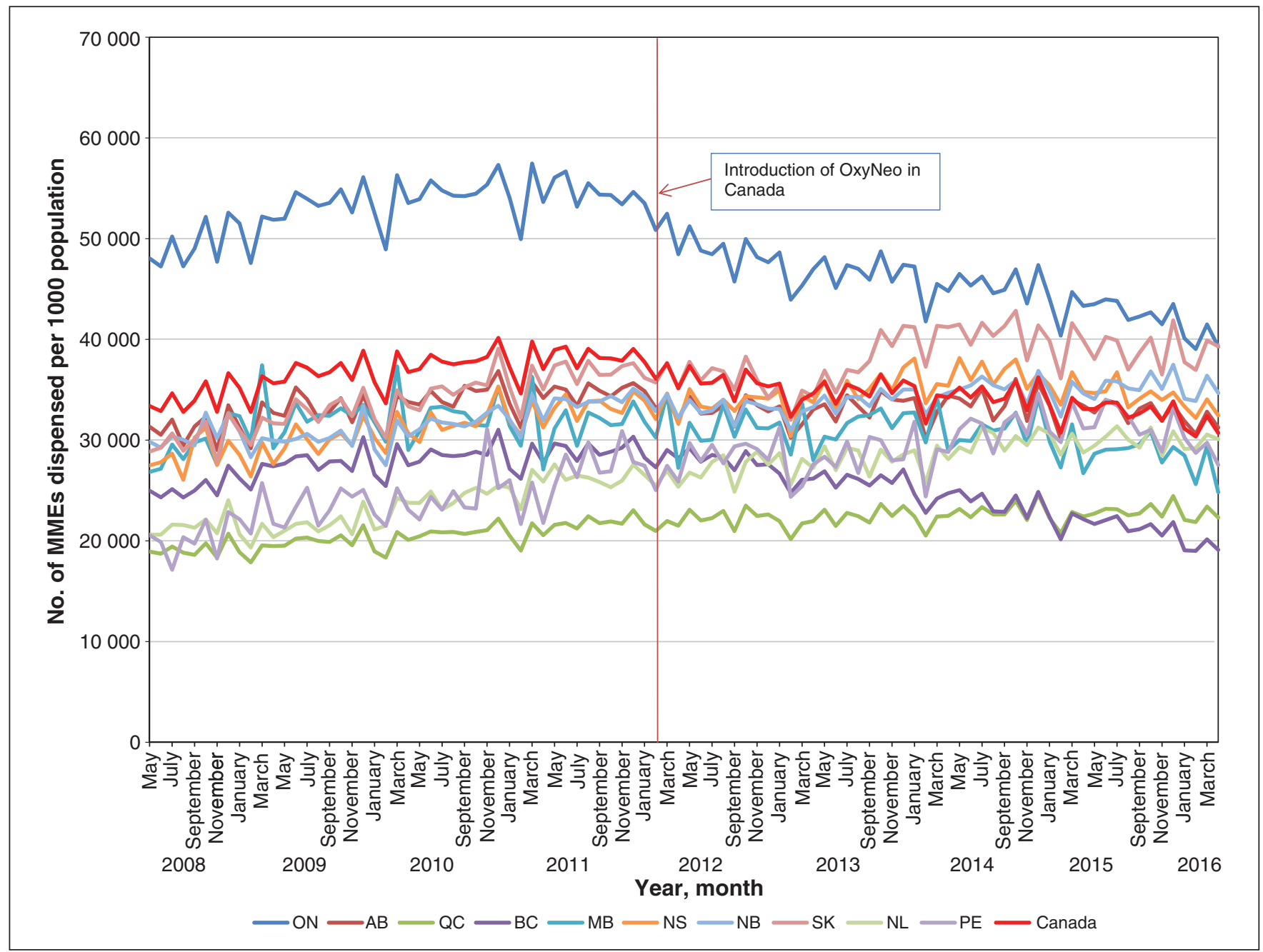

Figure 1: Rate of dispensing of long-acting opioids (in milligrams of morphine equivalents [MMEs] per 1000 population) in Canada, May 2008April 2016, by province. 
Overall use varied substantially by province (Figure 1). Ontario exhibited the highest levels of opioid dispensing throughout the study period, and Quebec consistently had the lowest levels. The monthly quantity of long-acting opioid dispensed fell by $14.9 \%$ between February 2012 (introduction of OxyNeo) and April 2016, from 36098 MMEs per 1000 population to $30716 \mathrm{MMEs}$ per 1000 population $(p<0.01)$. However, this impact varied across Canada. In Ontario and British Columbia, there were significant reductions in the overall quantity of long-acting opioids dispensed between February 2012 and April 2016, with rates falling by 22.8\% (from 50865 to $39288 \mathrm{MMEs}$ per 1000 population) $(p=0.01)$ and $30.0 \%$ (from 27306 to 19107 MMEs per 1000 population) $(p=0.01$ ), respectively. There were also significant changes in the rate of prescribing of long-acting opioids in Saskatchewan $(p=0.01)$, Quebec $(p<0.01)$ and New Brunswick $(p=0.05)$; however, these latter impacts were small, and overall rates of use of longacting opioids continued to rise in those provinces over the study period. In contrast, there were no significant changes in rates of dispensing of immediate-release formulations after OxyNeo was introduced ( $p>0.05$ in all models) (Figure 2), with rates climbing in most provinces. Although the rate of dispensing of immediate-release opioids declined over time in Nova Scotia and BC, the introduction of OxyNeo did not appear to be driving these changes ( $p=0.4$ and 0.8 , respectively).

Changes in the quantity of long-acting opioids dispensed varied considerably by opioid type. The national rate of oxycodone prescribing fell by $46.4 \%$ after the introduction of OxyNeo, from 14140 MMEs per 1000 in February 2012 to 7585 MMEs per 1000 at the end of the study period $(p<$ 0.001) (Figure 3). In contrast, the rate of hydromorphone dispensing increased by $47.8 \%$, from 4890 MMEs to 7227 MMEs per 1000 population over this same period $(p<$ 0.001 ), which indicates a likely partial substitution for oxycodone. We observed no significant changes in the dispensed quantities of long-acting morphine $(p=0.1)$, codeine $(p=0.7)$ or fentanyl $(p=0.7)$. By the last month of the study period, fentanyl made the largest single contribution to overall community exposure to long-acting opioids $(37.5 \%$ [11 510 MMEs per 1000 population]), followed by oxycodone (24.7\% [7585 MMEs per 1000 population]), hydromorphone (23.5\% [7227 MMEs per 1000 population]), morphine

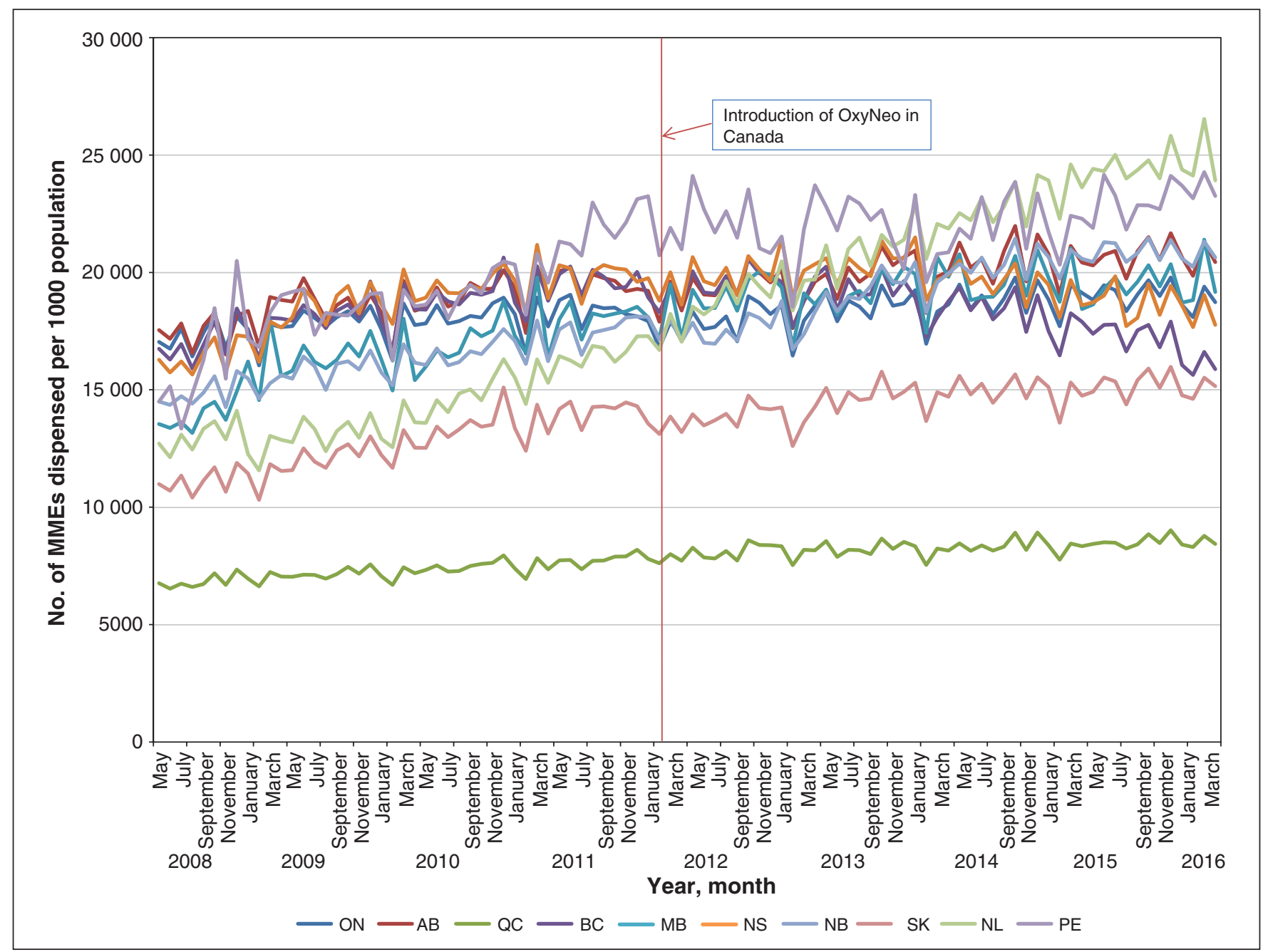

Figure 2: Rate of dispensing of immediate-release opioid dispensing (in milligrams of morphine equivalents [MMEs] per 1000 population) in Canada, May 2008-April 2016, by province. 


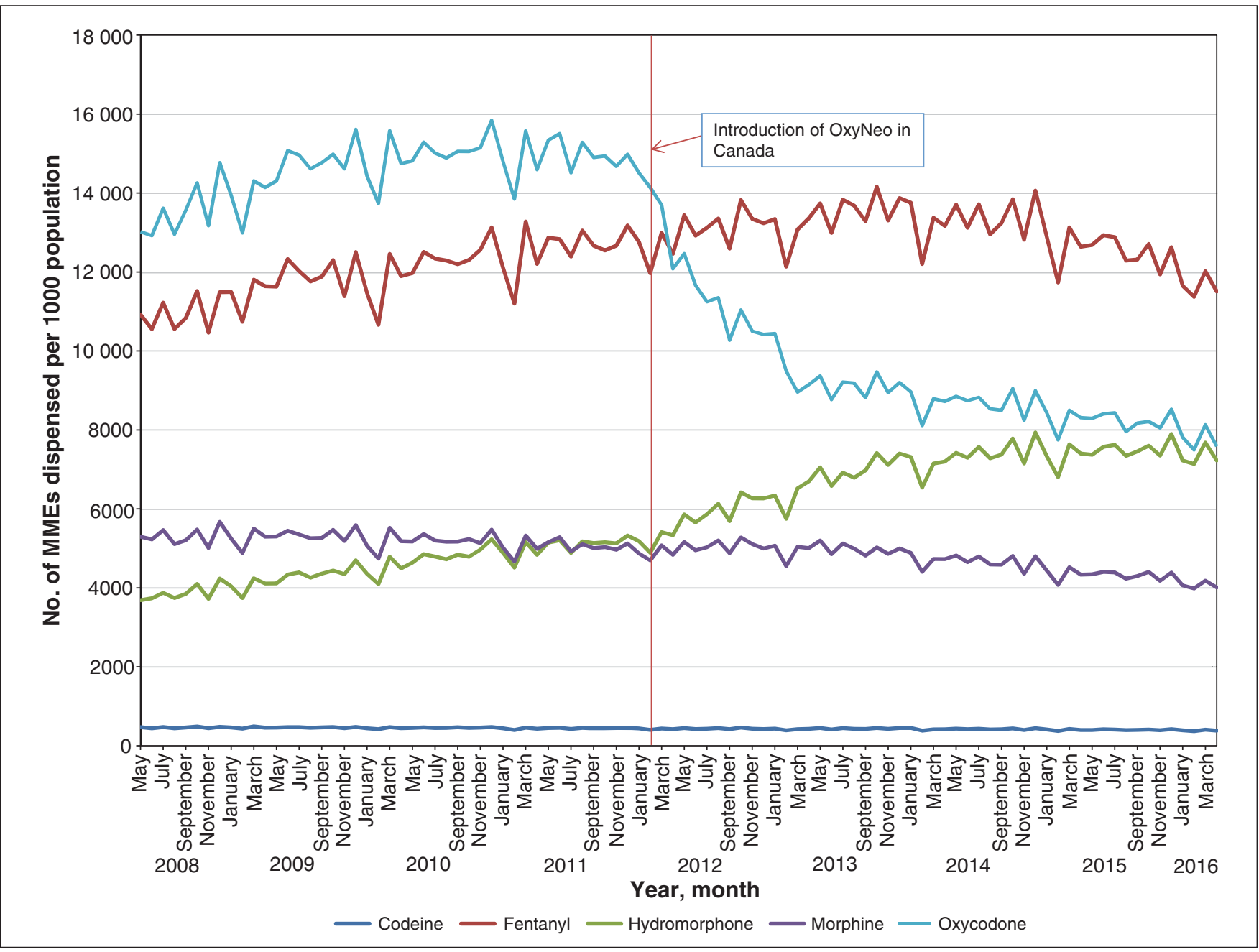

Figure 3: Rate of dispensing of long-acting opioids (in milligrams of morphine equivalents [MMEs] per 1000 population) in Canada, May 2008April 2016, by opioid type.

(13.0\% [4011 MMEs per 1000 population]) and codeine (1.2\% [383 MMEs per 1000 population]).

In the first 6 months of the study period, the number of units and the quantity of opioid dispensed per prescription varied considerably between provinces (Table 2). In Quebec, the average number of units dispensed per prescription was 32, with each prescription having 2153 MMEs on average. In contrast, in all the other provinces, the average number of opioid units dispensed per prescription ranged from 53 (BC) to 74 (Nova Scotia), and the average opioid quantity per prescription varied from 3162 MMEs (BC) to 4508 MMEs (Ontario). Although the rate of prescribing of long-acting opioids (prescriptions per 1000 population) increased over the study period, the number of units and total quantity (in MMEs) dispensed per prescription declined. The largest changes in prescription quantity were observed in Quebec, Ontario, BC and Nova Scotia, where the opioid quantity dispensed per prescription fell by $43.9 \%$ (Nova Scotia) to $47.5 \%$ (Quebec). In the last 6 months of the study period, Quebec continued to exhibit the lowest quantity of opioids dispensed per prescription (25 units per prescription; 1131 MMEs per prescription).
Before the introduction of OxyNeo, OxyContin accounted for the highest levels of population exposure to long-acting opioids in all provinces except for Saskatchewan, Manitoba and Quebec, where fentanyl dominated, and Nova Scotia, where hydromorphone dominated (Appendix 1). In provinces where OxyContin accounted for the greatest opioid exposure, there was a reduction in oxycodone quantity dispensed after OxyNeo was introduced. However, the extent of the decline varied. In Alberta, despite a rapid decline in dispensing, oxycodone remained dominant at the end of the study period. In contrast, in Ontario, BC and Prince Edward Island, declines in oxycodone exposure meant that fentanyl became the dominant long-acting opioid, and, in New Brunswick, hydromorphone became the dominant opioid.

\section{Interpretation}

In this population-based study spanning 8 years, we found that the introduction of $\mathrm{OxyNeo}$ against a background of changes in public drug benefit policy in some Canadian provinces was associated with significant reductions in the quantity 


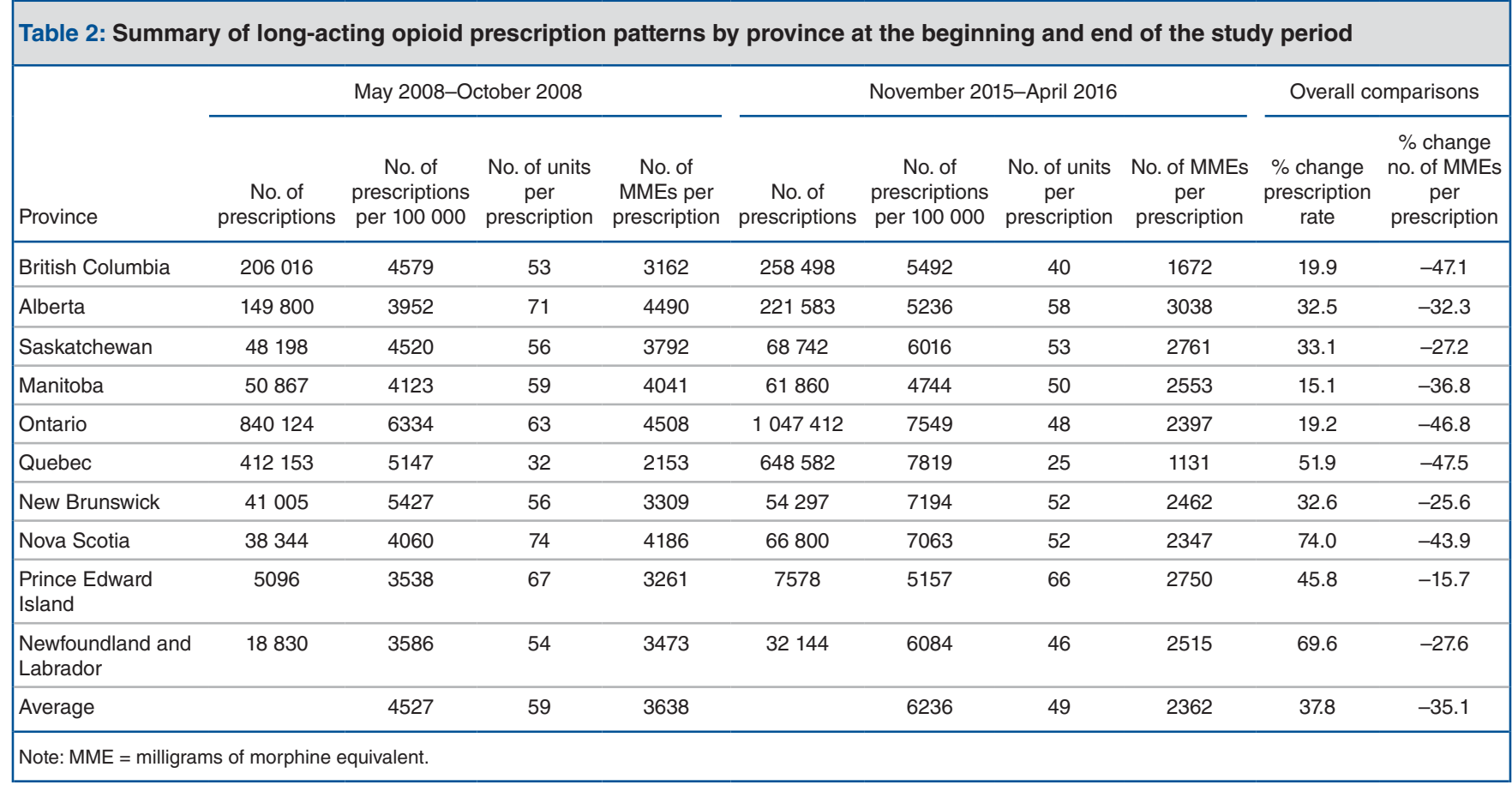

of long-acting opioids dispensed, with prescribing of longacting oxycodone declining dramatically and being partially replaced by increased dispensing of long-acting hydromorphone. Furthermore, our finding of no corresponding increase in dispensing of immediate-release opioids suggests that declining oxycodone dispensing outweighed increased rates of dispensing of other long-acting opioids.

These findings suggest that the introduction of a tamperdeterrent agent may have driven dispensing patterns toward other similar opioids within the same class that do not have tamper-deterrent properties. However, we cannot determine the extent to which accompanying changes to public drug formularies influenced these patterns. Recently, 2 large studies from the US also showed significant reductions in the quantity of long-acting oxycodone dispensed following the introduction of a tamper-deterrent formulation. ${ }^{18,19}$ In contrast to our findings, the authors reported no corresponding rise in the quantity of other long-acting opioids dispensed. These differences may be at least partially explained by changes in the public funding of OxyNeo in Canada, which may have led more patients to switch from oxycodone to an alternative opioid. We observed considerable interprovincial variation in the impact of the introduction of OxyNeo, which likely reflects both differences in patterns of opioid prescribing before this change and differences in provincial drug insurance plan policies (see Appendix 1 for a summary of listing status in each province). In particular, the national trend toward lower dispensing quantity of long-acting opioids was driven by 2 of the largest provinces in Canada, Ontario and BC. In both provinces, there were immediate, dramatic reductions in dispensing of long-acting oxycodone, such that by June 2012, only 4 months after the introduction of OxyNeo, oxycodone was no longer the dominant opioid in either province. This was likely driven, at least in part, by strict reimbursement criteria implemented in both provinces. ${ }^{20,21}$ Although we observed similar patterns of reduced dispensing of long-acting oxycodone in other provinces, the impact on overall opioid quantity dispensed outside of Ontario and $\mathrm{BC}$ was minimal. In most provinces, this is because dispensing of long-acting oxycodone was low, even before the tamper-deterrent formulation was introduced, and, therefore, small shifts away from oxycodone had limited impact on the total quantity of long-acting opioid dispensed. Two exceptions to this were New Brunswick and Alberta. In New Brunswick, long-acting oxycodone was high but was substantially influenced by the new formulation and strict reimbursement restrictions for this new product on the provincial drug insurance plan. ${ }^{11}$ Conversely, in Alberta, dispensing of long-acting oxycodone was high, and, despite a small decline in quantity in February 2012, it remained that way throughout the study period. This may have been due to the listing of tamper-deterrent long-acting oxycodone as a full benefit in Alberta, which did not require clinicians to shift patients to alternative opioids. ${ }^{11}$

These findings highlight the complex effects that can occur with the introduction of new tamper-deterrent agents in a medication class where other, non-tamper-deterrent options are provided. It appears that the introduction of a tamperdeterrent agent along with accompanying changes to listing status on public drug insurance programs in several provinces was associated with both significant replacement of oxycodone with other long-acting opioids and an overall reduction in the quantity of long-acting opioids dispensed. In the US, similar changes in opioid prescribing patterns following the introduction of tamper-deterrent oxycodone have been associated with increased reports of using heroin to get "high" 22 and accelerated rates of heroin overdoses. ${ }^{18}$ Although the impact of this 
new formulation on patient outcomes in Canada has not been studied, recent reports have shown that hospital admissions for heroin overdoses rose by $38 \%$ between fiscal years 2011/12 and 2012/13 in Canada and that heroin involvement in opioid-related deaths nearly doubled between 2012 and 2015 in Ontario. ${ }^{23,24}$ Despite our inability to determine the extent to which this was driven by changes in patterns of dispensing of long-acting opioids, these findings highlight a need for further exploration of the potential consequences of these shifts on patient outcomes.

\section{Strengths and limitations}

A key strength of this study is its capacity to report on quantity of prescribing of long-acting opioids across Canada over an 8-year period. However, several limitations bear mention. First, because our data included prescriptions dispensed from community pharmacies, we were unable to determine the impact of the introduction of OxyNeo on opioid prescribing in hospitals. Second, we did not have patient-level data and were thus unable to measure effects on the number of people prescribed opioids. This is important in the case of fentanyl, in which the high level of calculated population exposure may be concentrated in a relatively small number of people who are each receiving high opioid dosages. Third, we relied on projected estimates of prescription dispensing quantities, which include a small amount of sampling error. However, in Quebec, the province with the lowest rate of opioid prescribing, about $95 \%$ of all pharmacies are captured in the IMS Health Canada sample, which suggests that sampling bias is not the explanation for our finding of relatively low rates of dispensing in that province. Fourth, we did not specifically study changes in drug plan funding for opioids in our analysis and so could not determine how such changes influenced the observed trends in prescribing. Fifth, the Compuscript database does not have data from the territories in Canada, and therefore we were unable to include them in this analysis. Finally, we restricted our analyses to oral and transdermal opioid formulations with reliable morphine equivalence ratios. Given that these represent the majority of opioids prescribed across Canada, we do not expect that this exclusion influenced our findings.

\section{Conclusion}

The findings of this large, nationally representative study of opioid prescription patterns suggest that the introduction of a tamper-deterrent formulation of long-acting oxycodone, against a background of changes in public drug benefit policy, was associated with statistically significant, sustained changes in selection of long-acting opioids but only modest changes in the quantities of long-acting opioids dispensed. This illustrates the limited effect a tamper-deterrent formulation and associated coverage policy can have when other, non-tamperdeterrent alternatives are readily available. The considerable interprovincial variation shows the added influence of factors such as drug insurance policy and clinical practice on patterns of opioid use. These findings are of high importance given the potential for patient harm when switching between opioids of differing potency, as well as the potential for patients to transition to illicit opioids when access to prescription opioids is restricted.

\section{References}

1. Furlan AD, Sandoval JA, Mailis-Gagnon A, et al. Opioids for chronic noncancer pain: a meta-analysis of effectiveness and side effects. CMAF 2006;174: 1589-94.

2. Gomes T, Mamdani MM, Dhalla IA, et al. The burden of premature opioidrelated mortality. Addiction 2014;109:1482-8.

3. International Narcotics Control Board. Opioid consumption motion chart Madison (WI): Office of the Board of Regents; 2006. Available: https://ppsg. medicine.wisc.edu/chart (accessed 2017 Oct. 2).

4. Seya MJ, Gelders SF, Achara OU, et al. A first comparison between the consumption of and the need for opioid analgesics at country, regional, and global levels. F Pain Palliat Care Pharmacother 2011;25:6-18.

5. International Narcotics Control Board. Canada: opioid consumption in morphine equivalence (ME), mg per person. World Health Organization population data. Madison (WI): Pain \& Policy Studies Group, University of Wisconsin/WHO Collaborating Center; 2015. Available: www.painpolicy.wisc.edu/sites/www.painpolicy.wisc.edu/ files/country_files/morphine_equivalence/canada_me_methadone.pdf (accessed 2017 Oct. 2).

6. Reitsma ML, Tranmer JE, Buchanan DM, et al. The prevalence of chronic pain and pain-related interference in the Canadian population from 1994 to 2008. Cbronic Dis Inj Can 2011;31:157-64.

7. Dhalla IA, Mamdani MM, Sivilotti ML, et al. Prescribing of opioid analgesics and related mortality before and after the introduction of long-acting oxycodone. CMA7 2009;181:891-6.

8. Van Zee A. The promotion and marketing of OxyContin: commercial triumph, public health tragedy. Am 7 Public Health 2009;99:221-7.

9. Lipman AG. What have we learned from OxyContin? 7 Pain Palliat Care Pharmacother 2003;17:1-4.

10. Steffan RR. Timed-release oxycodone. Can Fam Physician 2013;59:612-3.

11. Prescribing and dispensing policies to address harms associated with prescription drug abuse. Environmental Scan; Issue 52. Ottawa: Canadian Agency for Drugs and Technologies in Health; 2015.

12. Gomes T, Mamdani MM, Paterson JM, et al. Trends in high-dose opioid prescribing in Canada. Can Fam Physician 2014;60:826-32.

13. Fischer $\mathrm{B}$, Jones $W$, Rehm J. Trends and changes in prescription opioid analgesic dispensing in Canada 2005-2012: an update with a focus on recent interventions. BMC Health Serv Res 2014;14:90.

14. National Opioid Use Guideline Group. Canadian guideline for safe and effective use of opioids for chronic non-cancer pain. Hamilton (ON): McMaster University; 2010. Available: http://nationalpaincentre.mcmaster.ca/opioid_2010/ (accessed 2017 Oct. 2).

15. Statistics Canada. CANSIM Table 051-0001. Population by year, by province and territory. Available: www.statcan.gc.ca/tables-tableaux/sum-som/101/cst01/ demo02a-eng.htm (accessed 2017 Oct. 2).

16. Lopez Bernal J, Cummins S, Gasparrini A. Interrupted time series regression for the evaluation of public health interventions: a tutorial. Int 7 Epidemiol 2017;46:348-55.

17. Gilmour S, Degenhardt L, Hall W, et al. Using intervention time series analyses to assess the effects of imperfectly identifiable natural events: a general method and example. BMC Med Res Methodol 2006;6:16.

18. Larochelle MR, Zhang F, Ross-Degnan D, et al. Rates of opioid dispensing and overdose after introduction of abuse-deterrent extended-release oxycodone and withdrawal of propoxyphene. 7AMA Intern Med 2015;175:978-87.

19. Hwang CS, Chang HY, Alexander GC. Impact of abuse-deterrent OxyContin on prescription opioid utilization. Pharmacoepidemiol Drug Saf 2015;24: 197-204.

20. BC PharmaCare Newsletter. Victoria: Pharmaceutical Services Division, British Columbia Ministry of Health; 2012. Available: www2.gov.bc.ca/assets/gov/ health/health-drug-coverage/pharmacare/newsletters/news12-004.pdf (accessed 2017 Oct. 2).

21. Important notice regarding change in funding status of oxycodone controlled release tablet - (discontinuation of OxyContin and introduction of OxyNeo North York (ON): Ontario Ministry of Health and Long-Term Care; 2012; Available: www.health.gov.on.ca/en/pro/programs/ohip/bulletins/4000/ bul4557_1.pdf (accessed 2017 Oct. 2).

22. Cicero TJ, Ellis MS. Abuse-deterrent formulations and the prescription opioid abuse epidemic in the United States: lessons learned from OxyContin. $7 A M A$ Psychiatry 2015;72:424-30.

23. Hospitalizations and emergency department visits due to opioid poisoning in Canada. Ottawa: Canadian Institute for Health Information; 2016.

24. Gomes T, Greaves S, Martins D, et al. Latest trends in opioid-related deaths in Ontario: 1991 to 2015. Toronto: Ontario Drug Policy Research Network; 2017. Available: http://odprn.ca/wp-content/uploads/2017/04/ ODPRN-Report_Latest-trends-in-opioid-related-deaths.pdf (accessed 2017 Oct. 2). 
Affiliations: Li Ka Shing Knowledge Institute of St. Michael's Hospital (Gomes); Institute for Clinical Evaluative Sciences (Gomes, Paterson, Greaves, Henry); Institute of Health Policy, Management, and Evaluation (Gomes, Paterson, Henry), University of Toronto; Leslie Dan Faculty of Pharmacy (Gomes), University of Toronto; Faculty of Arts and Sciences (Mastorakos), University of Toronto, Toronto, Ont.; Department of Family Medicine (Paterson), McMaster University, Hamilton, Ont.; College of Pharmacy (Sketris), Dalhousie University, Halifax, NS; Faculty of Health Sciences (Caetano), University of Manitoba; Provincial Drug Programs (Caetano), Government of Manitoba, Winnipeg, Man.; Centre for Research in Evidence-Based Practice (Henry), Bond University, Gold Coast, Australia

Contributors: Tara Gomes and David Henry acquired the data, and Andrea Mastorakos analyzed the data. Tara Gomes and Andrea Mastorakos drafted the article. All of the authors contributed to the conception and design of the study and the interpretation of the data, revised the manuscript critically for important intellectual content, gave final approval of the version to be published and agreed to be accountable for all aspects of the work.

Funding: This study was supported by the Canadian Network for Observational Drug Effect Studies, a collaborating centre of the Drug Safety and Effectiveness Network, which is funded by grant DSE-146021 from the Canadian Institutes of Health Research. The opinions, results, and conclusions reported in this paper are those of the authors.

Disclaimer: The statements, findings, conclusions, views and opinions contained and expressed in this publication are based in part on data obtained under licence from IMS Health Canada Inc. concerning CompuScript, May 2008 through April 2016. All rights reserved. The statements, findings, conclusions, views and opinions contained and expressed herein are not necessarily those of IMS Health Canada Inc. or any of its affiliated or subsidiary entities.

Canadian Network for Observational Drug Effect Studies Investigators: Samy Suissa (principal investigator), Colin R. Dormuth (British Columbia), Brenda R. Hemmelgarn (Alberta), Gary F. Teare (Saskatchewan), Patricia Caetano and Dan Chateau (Manitoba), David A. Henry and J. Michael Paterson (Ontario), Jacques LeLorier (Quebec), Adrian R. Levy (Atlantic: Nova Scotia, Newfoundland and Labrador, New Brunswick, Prince Edward Island), Pierre Ernst and Kristian B. Filion (UK Clinical Practice Research Datalink), Robert W. Platt (Methods) and Ingrid S. Sketris (Knowledge Translation).

Supplemental information: For reviewer comments and the original submission of this manuscript, please see www.cmajopen.ca/content/5/4/ E800/suppl/DC1. 